\title{
Akreditasyon Alanında Yapılan Lisansüstü Tezlerin İncelenmesi
}

\author{
Examination of Postgraduate Theses in Accreditation
}

\begin{tabular}{|c|c|}
\hline \multicolumn{2}{|r|}{ Serap Nur Duman } \\
\hline Yazar Bilgileri & ÖZ \\
\hline $\begin{array}{l}\text { Serap Nur Duman } \\
\text { Dr. Öğr. Üyesi, Kırıkkale } \\
\text { Üniversitesi, Eğitim Bilimleri, } \\
\text { serapnurcanoglu@gmail.com }\end{array}$ & $\begin{array}{l}\text { Akreditasyon; sunulan ürün ve hizmetlerin, kalite standartlarına ne düzeyde sahip } \\
\text { olduğunu belirleme sürecidir. Ürün ve hizmet çeşitliliğinin her geçen gün artmasıyla } \\
\text { eğitimden sağlığa kadar pek çok farklı alanda akreditasyon araştırmaları yapılmaktadır. Bu } \\
\text { araştırmalardan bazıları yükseköğretimde lisansüstü tez çalışmaları ile } \\
\text { gerçekleştirilmektedir. Bu araştırmada akreditasyon konusunda yapılan lisansüstü tezler } \\
\text { incelenerek, yükseköğretim düzeyinde yapılan akreditasyon araştırmalarına yönelik } \\
\text { kapsamlı bir değerlendirme çalışması yapmak amaçlanmıştır. Araştırma betimsel araştırma } \\
\text { modelinde tasarlanmıştır. Araştırmanın çalışma grubunda, 1994-2019 yılları arasında } \\
\text { akreditasyon ile ilgili gerçekleşen ve erişime açık } 220 \text { lisansüstü tezin tamamı yer almıştır. } \\
\text { Bu nedenle evrenin tamamı araştırmada yer almıştır. Araştırmada yer alan tezlerin } \\
\text { incelemesinde doküman analizinden yararlanılmıştır. Elde edilen bulgular; tez yazarlarının } \\
\text { cinsiyetine göre; tezlerin yapıldığı üniversiteye, enstitüye ve anabilim dallarına göre; } \\
\text { tezlerde kullanılan araştırma yöntemi, araştırma modeli, veri toplama aracı ve örneklemine } \\
\text { göre ve son olarak tezlerin konularına göre detaylı olarak tablolar halinde sunulmuş ve } \\
\text { yorumlanmıştır. Tezlerin çoğunlukla sosyal bilimler enstitüsüne bağlı işletme / işletme } \\
\text { yönetimi anabilim dallarında gerçekleştiği ve tarama modelinde yapıldığına ulaşılmıştır. } \\
\text { Bunun yanında tezlerde kullanılan veri toplama araçlarının genellikle anket ve doküman } \\
\text { inceleme formu olduğu belirlenmiştir. Akreditasyon ile ilgili yapılan lisansüstü tez } \\
\text { çalışmaları genellikle sağlık ve eğitim konularında tamamlanmıştır. }\end{array}$ \\
\hline
\end{tabular}

\section{Makale Bilgileri}

Anahtar Kelimeler

Akreditasyon

Lisansüstü Eğitim

Yükseköğretim

Değerlendirme

\section{Keywords}

Accreditation

Postgraduate Education

Higher Education

Evaluation

\author{
Makale Geçmişi \\ Geliş: 11.11.2020 \\ Düzeltme: 20.11.2020 \\ Kabul: 30.12.2020
}

\begin{abstract}
Accreditation; It is the process of determining the level of quality standards of the products and services offered. With the increasing variety of products and services, accreditation studies are carried out in many different areas from education to health. Some of these researches are carried out with postgraduate thesis studies in higher education. In this study, it is aimed to make a comprehensive evaluation study for accreditation studies conducted at higher education level by examining the postgraduate theses on accreditation. The research is designed in a descriptive research model. In the study group of the research, all 220 graduate theses related to accreditation between 1994 and 2019 were included. Therefore, the entire universe took part in the research. Document analysis was used to examine the theses in the research. Findings obtained; according to the gender of the thesis authors; According to the university, institute and departments where the theses were made; The research method, research model, data collection tool and sample used in the dissertations were presented and interpreted in tables in detail according to the topics of the theses. It has been found that the theses are mostly carried out in the departments of business / business management affiliated to the social sciences institute and they are made in a scanning model. In addition, it has been determined that the data collection tools used in theses are generally questionnaire and document review form. Postgraduate thesis studies on accreditation have generally been completed on health and education issues.
\end{abstract}




\section{Giriş}

Küreselleşen dünyada bilimin ve teknolojinin her geçen gün gelişmesiyle birlikte sağlık, eğitim, mühendislik gibi çalışma alanlarının kendini yenileyerek kalite standartlarını koruması bir zorunluluk haline gelmektedir. Mühendislikte MÜDEK (Mühendislik Değerlendirme Kurulu), sağlıkta TÜSKA (Türkiye Sağlık Hizmetleri Kalite ve Akreditasyon Enstitüsü) ve eğitimde YÖK (Yükseköğretim Kurulu) akreditasyon süreçlerinin uygulanması, yönetilmesi ve sürdürülmesinde öncülük etmektedir (Aktan ve Gencel, 2010; Cengiz, 2018; Günay, 2003).

Eğitimde akreditasyon ihtiyacının ortaya çıması ise eğitimde yer alan kurum ve kuruluşlarının çeşitlenmesi ve artması ile olmuştur. Ulusal ve uluslararası düzeyde pek çok üniversitenin eğitim hizmeti sunması ile birlikte yükseköğretim kurumlarının ve sundukları eğitim hizmetinin niteliğinin belirlenmesi ve birbirleriyle karşılaştırılması ihtiyacı ortaya çıkmıştır. Bu sayede hem yükseköğretimde yer alan öğretim elemanlarının ve eğitim programlarının değerlendirilmesi yapılarak gelişimine katkıda bulunmak hem de yükseköğretimden mezun olan öğrencilerin iş hayatında kendilerinden beklenilen niteliklere sahip olup olmadıklarını araştırmak hedeflenmektedir. Aynı zamanda aynı alanda eğitim hizmeti sunan pek çok farklı üniversitenin de birbirleri ile karşılaştırılması yapılarak yükseköğretimde rekabeti artırmak amaçlanmaktadır. Tüm bunları gerçekleştirebilmek, yükseköğretimde kalite anlayışına hizmet eden araçlarının geliştirilmesine bağlıdır (Uçar ve Levent, 2017). Yükseköğretimde kaliteyi sağlamaya yönelik kullanılan araçlardan biri akreditasyon uygulamalarıdır. Latince kökenli Fransızca bir sözcük olan akreditasyon, güvenilir ve inanılır olma hali anlamına gelmektedir (Doğan, 1999). Yükseköğretimde akreditasyon ise; yükseköğretim kurumlarında sürdürülen eğitim ve uygulamaların ulusal ve uluslararası düzeyde kalite ve verimlilik standartlarına sahip olduğunu belgeleyen bir süreçtir (Aktan ve Gencel, 2010). Bu sürecin başarılı uygulayıcılarından biri olan ENQA (European Association for Quality Assurance in Higher Education), Avrupa genelinde yükseköğretim kalite güvence faaliyetlerinden sorumlu kuruluşlardan biridir. ENQA, Avrupa yükseköğretim alanında iyi uygulamaları yaygınlaştırmak ve işbirliğini artırmak amacıyla yükseköğretimde kalite güvencesini sağlamayı hedeflemektedir (YÖK, 2020a). Türkiye'de yükseköğretimde kalite güvence sisteminin kurulmasından ve sürdürülmesinden sorumlu kuruluş ise Yükseköğretim Kuruludur. Bu kurul, Avrupa yükseköğretim alanında yapılan kalite güvence çalışmaları kapsamına uygun olarak 2005 yılında Yükseköğretim Kurumlarında Akademik Değerlendirme ve Kalite Geliştirme Yönetmeliği yayınlanmıştır. Bu yönetmelik çerçevesinde tüm yükseköğretim kurumları kendi kalite güvence sistemlerinden sorumlu tutularak belirlenen sürede yükseköğretim kalite standartlarına ulaşmak zorundadır (Iş̧ı ve Beykoz, 2018; Özçiçek ve Karaca, 2019; YÖK, 2020b). 
Türkiye'de yükseköğretimde kalite çalışmalarının önem kazandığı bu süreçte, akreditasyon sürecinde yapılan çalışmaların ve uygulamaların değerlendirilmesi gerekli görülmektedir. Bu sayede yükseköğretimde akreditasyon sürecinin anlaşılması, akreditasyon sürecinde yapılan uygulamaların değerlendirilmesi ve yaygınlaştırılması sağlanabilecektir. Aynı zamanda yükseköğretim sisteminde akreditasyon çalışmalarının hangi alanlarda öne çıktığının belirlenmesi ve hangi alanlarda akreditasyon uygulamalarına ihtiyaç duyulduğunu ortaya koymak adına akreditasyon sürecinde yapılan lisansüstü tezlerin değerlendirilmesi gerekmektedir. Literatür taramasında akreditasyon ile ilgili çalışmaları inceleyen kapsamlı bir araştırmaya rastlanamamıştır. Bu nedenle bu araştırma ile akreditasyon ile ilgili lisansüstü tezlerin kapsamlı incelemesini gerçekleştirmek amaçlanmıştır. Araştırma kapsamında incelenen tezler ile akreditasyon sürecinde çalışan üniversitelere, enstitülere, anabilim dallarına yönelik incelemeler yapılmış; aynı zamanda akreditasyon hakkında yapılan tezlerin konuları, yöntemleri, veri toplama araçları ve örneklemleri ayrıntılı olarak ortaya konulmuştur. Böylelikle akreditasyon hakkında araştırmaya ihtiyaç duyulan alanların, konuların belirlenmesi ve elde edilen bulgulara dayalı olarak yapılacak yeni akreditasyon araştırmalarına rehberlik etmek amaçlanmıştır.

\section{Yöntem}

$\mathrm{Bu}$ araştırmada betimsel araştırma modelinden yararlanılmıştır. Betimsel araştırmalar, var olan ve devam eden olguları derinlemesine açılayan araştırmalardır (Sönmez ve Alacapınar, 2013, s. 48). Araştırmada 1994-2019 yılları arasında akreditasyon konusunda yapılan lisansüstü tezlerin analiz edilmesinde doküman analizi kullanıldığı için araştırma nitel araştırma özelliği de taşımaktadır. Nitel araştırmalar gözlem, görüşme, doküman analizi gibi veri toplama yöntemlerinin tercih edildiği ve olayların gerçekçi bir yaklaşımla ortaya konulduğu araştırmalardır (Yıldırım ve Şimşek, 2013, s. 45).

\section{Çalışma Grubu}

Araştırmanın çalışma grubunu, 1994-2019 yılları arasında gerçekleşen ve Ulusal Tez Merkezi'nde erişime açık olan 220 yüksek lisans ve doktora tezi oluşturmaktadır. Bu nedenle örneklem belirleme yoluna gidilmemiş, evrenin tamamı araştırmaya dahil edilmiştir. Araştırmada yer alan tezlerin yıllara göre dağılımı Tablo 1'de, düzeylerine göre dağılımı ise Tablo 2' de sunulmuştur.

Tablo 1. Araştırmada Yer Alan Tezlerin Yıllara Göre Dağılımı

\begin{tabular}{cccccc}
\hline Yıl & Tez Sayısı & $Y \imath l$ & Tez Sayısı & $Y \imath l$ & Tez Sayısı \\
\hline 1994 & 1 & 2006 & 5 & 2013 & 11 \\
1998 & 1 & 2007 & 11 & 2014 & 15 \\
2000 & 1 & 2008 & 8 & 2015 & 15 \\
2001 & 3 & 2009 & 10 & 2016 & 19 \\
2002 & 1 & 2010 & 26 & 2017 & 8 \\
2003 & 4 & 2011 & 10 & 2018 & 13 \\
2004 & 1 & 2012 & 10 & 2019 & 37 \\
2005 & 10 & \multicolumn{5}{c}{ Toplam (1994-2019) } & 220 \\
\hline \multicolumn{6}{c}{}
\end{tabular}


Tablo 2. Araştırmada Yer Alan Tezlerin Düzeylerine Göre Dağılımı

\begin{tabular}{lc}
\hline Tez Düzeyleri & Tez Sayısı \\
\hline Yüksek Lisans & 167 \\
Doktora & 53 \\
\hline Toplam & 220 \\
\hline
\end{tabular}

\section{Veri Toplama Araçları}

Araştırmanın örneklemini oluşturan tezlerin toplanmasında veri toplama aracı olarak belirtke tablosu kullanılmıştır (Ek 1). Anahtar kelime ve tezin tamamlandığı yıllar olmak üzere iki boyutlu olarak araştırmacı tarafından hazırlanan belirtke tablosu aracılı̆̆ıyla tezler sınıflandırılmıştır. Belirtke tablosunda tezlerin seçiminde kullanılan anahtar kelime "akreditasyon" dur. Bu yönüyle akreditasyon ile ilgili 1994-2019 aralığında yapılan erişime açık tüm tezlerin incelenmesi amaçlanmıştır. Bu sayede farklı araştırma konularında olsa dahi akreditasyon ile ilgili olan tüm tezlerin incelemesi gerçekleştirilmiştir. Özellikle akreditasyon hakkında çok fazla tez yapılmadığı için var olan tüm tezleri araştırmaya dâhil etmek için "akreditasyon" anahtar kelimesi ile tarama gerçekleştirilmiştir. Bu arama yapılırken "akreditasyon" kelimesi "tümü" alanında taratılmıştır. Tez adı, yazar, danışman, konu, dizin, özet dâhil tüm araçlarında tarama gerçekleştirilmiştir.

\section{Verilerin Toplanması}

Araştırmanın örneklemini oluşturan tezler, Ulusal Tez Merkezi'nin resmi web sayfasından doğrudan erişim sağlanarak toplanmıştır. Veri toplama sürecinde, lisansüstü tezler hiçbir müdahalede bulunulmadan araştırmacılar tarafından kaydedilmiştir. Tezlerin doğruluğunu ve güvenirliğini kontrol etmek amacıyla, araştırmada yer almayan bir eğitim bilimleri uzmanı Ulusal Tez Merkezi'nin resmi sayfasından "akreditasyon" anahtar kelimesini kullanarak yeniden tarama gerçekleştirmiş ve sonucu karşılaştırmıştır. Lisansüstü tezlerin belirtke tablosu ile sınıflandırılmasında ise farklı bir eğitim bilimleri uzmanının görüşüne başvurularak onayı alınmıştır. Böylelikle lisansüstü tezler veri analizi için uygun hale getirilmiştir (Creswell, 2017, s. 289).

\section{Verilerin Analizi}

Araştırmada verilerin analizi gerçekleştirilirken doküman analizinden yararlanılmıştır. Doküman analizi sürecinde; dokümanlara ulaşma, orijinalliği (özgünlüğü) kontrol etme, dokümanları anlama, veriyi analiz etme ve veriyi kullanma şeklinde beş basamak gerçekleştirilmektedir (Forster, 1995'den aktaran Yıldırım ve Şimşek, 2013, s. 223). Bu aşamalara dayalı olarak verilerin doküman analizi yapılırken takip edilen işlemler şunlardır:

- Dokümanlara ulaşma basamağında; Ulusal Tez Merkezi'nde "akreditasyon" anahtar kelimesi tarama yapılmış ve ulaşılan tezler araştırmacı tarafından kaydedilmiştir. 
- Özgünlüğü kontrol etme basamağında; lisansüstü tezlerin farklı zamanlarda Ulusal Tez Merkezi'nde yeniden araması yapılmıştır. Bunun yanında araştırmada yer almayan bir eğitim bilimleri uzmanı aynı anahtar kelimeyi kullanarak tezlere erişim sağlamıştır.

- Dokümanları anlama basamağında; kullanılan anahtar kelimenin lisansüstü tezlere ulaşmak için kullanışl1lı̆̆ı, doğruluğu ve geçerliği hakkında araştırmada yer almayan dört eğitim bilimleri uzmanının görüşüne başvurulmuştur. Bu uzmanlar araştırmada kullanılan belirtke tablosunun kapsam geçerliğine yönelik ortak şekilde olumlu görüş belirttikleri için belirtke tablosunda herhangi bir değişiklik yapılmamıştır.

- Veriyi analiz etme basamağında; lisansüstü tezlerin analizi yapılırken betimsel analizden yararlanılmıştır. Betimsel analiz sürecine uygun olarak önceden belirlenen temalar kapsamında tezler incelenmiştir. Betimsel analizde temalar belirlenirken öncelikle literatür taraması yapılmış ve analizde kullanılabilecek temalara yönelik dört eğitim bilimleri uzmanının görüşü alınmıştır. Bu temalar ile tezlerin yazarlarının cinsiyetine göre ve tezlerin üniversitelere, enstitülere, anabilim dallarına, araştırma yöntemlerine, araştırma modellerine, veri toplama aracına, örneklemine, araştırma konusuna göre dağılımları bulgularda sunulmuştur.

- Veriyi kullanma basamağında; analiz sonucu elde edilen bulgular tablolar halinde sunulmuş ve yorumlanmıştır.

Doküman analizi sonucu elde edilen bulgular tablolar halinde bulgular başlığında sunulmuştur. Hazırlanan bu tabloların bazılarında toplam değerler, toplam tez sayısından farklılık göstermektedir. Örneğin; araştırmada yer alan tezlerin veri toplama araçlarına göre dağılımı başlıklı tabloda toplam değer 220 yerine 227' dir. Bu durum; bazı tezlerde ayn anda birden fazla veri toplama aracının kullanılmasından kaynaklanmaktadır. Böyle tablolar, bulgular başlığında detaylı açıklanmıştır.

\section{Geçerlik ve Güvenirlik:}

Araştırmanın geçerlik ve güvenirlik önlemleri alınırken nitel araştırmaların doğasına uygun hareket edilmiştir. Buna dayalı olarak; araştırmanın amacı net ve anlaşılır şekilde ifade edilmiş, araştırmanın amacına uygun olarak yöntemi detaylı açıklanmıştır. Araştırmanın her aşaması hem okuyucular hem de araştırmacılar için ayrıntılı olarak raporlanmıştır. Bunun yanında araştırma sürecinde birbirinden bağımsız eğitim bilimleri uzmanlarının görüşüne başvurulmuş ve onayı alınmıştır (Yıldırım ve Şimşek, 2013, s. 291-296). 


\section{Bulgular}

Bu bölümde, araştırmanın amacına yönelik elde edilen bulgular tablolar halinde sunulmuş ve yorumlanmıştır.

\section{Tezlerin Yazarlarının Cinsiyete Göre Dağılımı}

Araştırmada yer alan tezlerin yazarlarının cinsiyete göre dağılımı Tablo 3'de yer almaktadır.

Tablo 3. Araştırmada Yer Alan Tezlerin Yazarlarının Cinsiyete Göre Dağılımı

\begin{tabular}{lc}
\hline Tez Yazarlan & Tez Sayısı \\
\hline Kadın & 111 \\
Erkek & 109 \\
\hline Toplam & 220 \\
\hline
\end{tabular}

Tablo 3'de görüldüğü gibi akreditasyon konusunda tez yazan kadınlar (\%50.45) ve erkekler (\%49.54) birbirine yakın sayıdadır. Buna dayalı olarak akreditasyon konusunda yapılan tez çalışmalarının cinsiyete göre dengeli dağılım gösterdiğine ulaşılmıştır.

\section{Tezlerin Üniversitelere Göre Dağılımı}

Araştırmada yer alan tezlerin üniversitelere göre dağılımı Tablo 4'de yer almaktadır.

Tablo 4. Araştırmada Yer Alan Tezlerin Üniversitelere Göre Dağılımı

\begin{tabular}{|c|c|c|c|c|c|c|c|c|c|c|}
\hline \multirow[b]{2}{*}{$Y a l$} & \multicolumn{10}{|c|}{ Üniversite } \\
\hline & Gazi & $\begin{array}{c}\text { Dokuz } \\
\text { Eylül }\end{array}$ & Marmara & $\begin{array}{c}\text { İstanbul } \\
\text { Teknik }\end{array}$ & Hacettepe & Ístanbul & Ankara & Beykent & Diğer & Toplam \\
\hline 1994 & & & & & & 1 & & & & 1 \\
\hline 1998 & & & & & & & & & 1 & 1 \\
\hline 2000 & & 1 & & & & & & & & 1 \\
\hline 2001 & & 1 & & & 1 & 1 & & & & 3 \\
\hline 2002 & & & & & & & & & 1 & 1 \\
\hline 2003 & & & 1 & 1 & & 1 & & & 1 & 4 \\
\hline 2004 & & & & & & & & & 1 & 1 \\
\hline 2005 & & 1 & 1 & & 2 & 1 & 1 & & 4 & 10 \\
\hline 2006 & 2 & 1 & 1 & & & & & & 1 & 5 \\
\hline 2007 & 1 & & 1 & & & 1 & 1 & & 7 & 11 \\
\hline 2008 & 1 & & 2 & & & & 1 & & 4 & 8 \\
\hline 2009 & & 2 & 1 & & 1 & & & & 6 & 10 \\
\hline 2010 & 2 & 1 & 4 & 3 & 3 & 2 & 2 & & 9 & 26 \\
\hline 2011 & 1 & 2 & 1 & & 1 & & 1 & & 4 & 10 \\
\hline 2012 & & 2 & 1 & 1 & & & & & 6 & 10 \\
\hline 2013 & 3 & 1 & & 1 & & & & 2 & 4 & 11 \\
\hline 2014 & 2 & & & 2 & 1 & & & 2 & 8 & 15 \\
\hline 2015 & 1 & 1 & 1 & 2 & & & & 1 & 9 & 15 \\
\hline 2016 & 1 & & & 1 & & 1 & 1 & 1 & 14 & 19 \\
\hline 2017 & 2 & & 1 & & & & & & 5 & 8 \\
\hline 2018 & & 2 & & 1 & & & & & 10 & 13 \\
\hline 2019 & 3 & 3 & 2 & 1 & 2 & 2 & 2 & 2 & 20 & 37 \\
\hline Toplam & 19 & 18 & 17 & 13 & 11 & 10 & 9 & 8 & 115 & 220 \\
\hline
\end{tabular}

Akreditasyon ile ilgili yapılan tezlerin üniversitelerine göre dağılımına ilişkin Tablo 4 hazırlanırken, 1994-2019 yılları arasında toplam tez sayısı 8 ve üzeri olan üniversiteler tabloda kendi adıyla belirtilmiş, toplam tez sayısı 8 'in altında olan üniversiteler ise diğer başlığında birleştirilerek 
tabloya eklenmiştir. Tablo 4 incelendiğinde akreditasyon ile ilgili en çok tezin sırasıyla Gazi Üniversitesi'nde (\%8.63), Dokuz Eylül Üniversitesi'nde (\%8.18) ve Marmara Üniversitesi'nde (\%7.72) yapıldığı belirlenmiştir. Bunun yanında İstanbul Teknik Üniversitesi, Hacettepe Üniversitesi ve İstanbul Üniversitesi gibi üniversitelerde de akreditasyon ile ilgili önemli sayıda tez yazıldığına ulaşılmıştır. Diğer başlı̆̆ında; Anadolu Üniversitesi (6 tez), Selçuk Üniversitesi (6 tez), Süleyman Demirel (6 tez), Sakarya Üniversitesi (5 tez), Yeditepe Üniversitesi (5 tez), Orta Doğu Teknik Üniversitesi (4 tez) gibi çok sayıda üniversitenin de akreditasyon konusunda tez çalışmalarının bulunduğu anlaşılmıştır. Diğer kategorisinde yer alan üniversitelerden otuz dördü akreditasyon alanında yalnızca 1 tez yapmıştır. Bu üniversitelerle birlikte akreditasyona yönelik yetmiş dokuz üniversitede tez yapıldığına ulaşılmıştır.

\section{Tezlerin Enstitülere Göre Dağılımı}

Araştırmada yer alan tezlerin enstitülere göre dağılımı Tablo 5'de yer almaktadır.

Tablo 5. Araştırmada Yer Alan Tezlerin Enstitülere Göre Dağılımı

\begin{tabular}{|c|c|c|c|c|c|c|c|c|c|c|}
\hline \multirow[b]{2}{*}{ Yil } & \multicolumn{10}{|c|}{ Enstitü } \\
\hline & $\begin{array}{c}\text { Sosyal } \\
\text { Bil. }\end{array}$ & $\begin{array}{l}\text { Fen } \\
\text { Bil. }\end{array}$ & $\begin{array}{l}\text { Săğlkk } \\
\text { Bil. }\end{array}$ & $\begin{array}{c}\text { Ĕ̌itim } \\
\text { Bil. }\end{array}$ & $\begin{array}{c}\text { Lisans } \\
\text { üstï } \\
\text { Ĕgitim }\end{array}$ & $\begin{array}{c}\text { Adli Tıp } \\
\text { ve Adli } \\
\text { Bilimler }\end{array}$ & $\begin{array}{c}\text { Güzel } \\
\text { Sanatlar }\end{array}$ & Bilişim & Enerji & Toplam \\
\hline 1994 & & & & & & 1 & & & & 1 \\
\hline 1998 & & 1 & & & & & & & & 1 \\
\hline 2000 & & & & 1 & & & & & & 1 \\
\hline 2001 & 1 & 1 & 1 & & & & & & & 3 \\
\hline 2002 & & 1 & & & & & & & & 1 \\
\hline 2003 & 2 & 1 & & 1 & & & & & & 4 \\
\hline 2004 & 1 & & & & & & & & & 1 \\
\hline 2005 & 1 & 4 & 2 & 3 & & & & & & 10 \\
\hline 2006 & 1 & 2 & & 2 & & & & & & 5 \\
\hline 2007 & 5 & 4 & 2 & & & & & & & 11 \\
\hline 2008 & 3 & 3 & & 2 & & & & & & 8 \\
\hline 2009 & 7 & 1 & 2 & & & & & & & 10 \\
\hline 2010 & 8 & 10 & 6 & 2 & & & & & & 26 \\
\hline 2011 & 5 & 1 & 1 & 2 & & & 1 & & & 10 \\
\hline 2012 & 4 & 1 & 2 & 3 & & & & & & 10 \\
\hline 2013 & 5 & 6 & & & & & & & & 11 \\
\hline 2014 & 7 & 6 & & 1 & & & & & 1 & 15 \\
\hline 2015 & 10 & 4 & & 1 & & & & & & 15 \\
\hline 2016 & 13 & 3 & 3 & & & & & & & 19 \\
\hline 2017 & 3 & & 4 & 1 & & & & & & 8 \\
\hline 2018 & 5 & 2 & 4 & 2 & & & & & & 13 \\
\hline 2019 & 13 & 6 & 9 & 4 & 3 & 1 & & 1 & & 37 \\
\hline Toplam & 94 & 57 & 36 & 25 & 3 & 2 & 1 & 1 & 1 & 220 \\
\hline
\end{tabular}

Tablo 5'de görüldüğü gibi, akreditasyon konusunda yapılan tezler en çok sırasıyla sosyal bilimler enstitüsünde (\%42.72), fen bilimleri enstitüsünde (\%25.90), sağlık bilimleri enstitüsünde (\%16.36) ve eğitim bilimleri enstitüsünde (\%11.36) gerçekleştirilmiştir. Bu durum, akreditasyon 
hakkında yapılan tez çalışmalarında sosyal bilimlerin ve fen bilimlerinin çoğunlukta olduğunu göstermektedir. Bu çalışmalar incelendiğinde sosyal bilimlerde öğretmen yetiştirme programlarının kazandırdığı öğretmen yeterliliklerini standartlara göre değerlendirme, Türkiye eğitim politikalarının değerlendirilmesi, Erasmus programı, okul yöneticilerinin yetiştirilmesinin karşılaştırılması, yükseköğretim hizmet kalitesi, kobilerin kalite sorunları, ortaöğretimde kalite denkliği, kalite akreditasyonu gibi farklı konuların çalışıldığı belirlenmiştir. Fen bilimlerinde ise laboratuvar uygulamalarında kalite güvenliği, eko yönetim sistemi, entegre yönetim sistemleri, mühendis eğitimine ilişkin talepler, ormancılık uygulamalarında akreditasyon, gıda analizi, laboratuvarlar arası karşılaştırma, sağlık yapılarında akreditasyon gibi başlıklarda çalışmalar tamamlanmıştır. Bunun yanında lisansüstü eğitim, adli tıp ve adli bilimler, güzel sanatlar, bilişim ve enerji enstitülerinde akreditasyona yönelik tezlerin yapılmış olması, akreditasyonun farklı disiplinlerde de tez konusu olarak çalışmaya başlandığını göstermektedir.

\section{Tezlerin Anabilim / Bilim Dallarına Göre Dağılımı}

Araştırmada yer alan tezlerin anabilim dallarına göre dağılımı Tablo $6^{\prime}$ da yer almaktadır.

Tablo 6. Araştırmada Yer Alan Tezlerin Anabilim Dallarına Göre Dağılımı

\begin{tabular}{|c|c|c|c|c|c|c|c|c|c|c|}
\hline \multirow[b]{2}{*}{$Y_{1} l$} & \multicolumn{10}{|c|}{ Anabilim Dalt } \\
\hline & $\begin{array}{l}\text { İşletme } \\
\text { / } \\
\text { Issletme } \\
\text { Yön. }\end{array}$ & $\begin{array}{l}\text { Sağhlk Yön./ } \\
\text { Sağllk } \\
\text { Kurumları İşl./ } \\
\text { Sağglkta Kalite } \\
\text { Geliş. ve } \\
\text { Akreditasyon } \\
\end{array}$ & $\begin{array}{c}\text { Elektrik Elektronik } \\
\text { Müh./ Bilgisayar } \\
\text { Müh./ Endüstri } \\
\text { Müh./ Biyomedikal } \\
\text { Müh./ Gıda Müh. }\end{array}$ & Ë̆itim & $\begin{array}{c}\text { Eğitim } \\
\text { Prog. ve } \\
\text { Öğr. }\end{array}$ & $\begin{array}{c}\text { Hemşirelik/ } \\
\text { Hemşirelikte } \\
\text { Yönetim }\end{array}$ & Mimarlik & $\begin{array}{l}\text { Ĕ̆it. } \\
\text { Yön. }\end{array}$ & Diğer & Top. \\
\hline 1994 & & & & & & & & & 1 & 1 \\
\hline 1998 & & & & & & & & & 1 & 1 \\
\hline 2000 & & & & & 1 & & & & & 1 \\
\hline 2001 & & & & & & & 1 & & 2 & 3 \\
\hline 2002 & & & 1 & & & & & & & 1 \\
\hline 2003 & 2 & & & & & & & & 2 & 4 \\
\hline 2004 & 1 & & & & & & & & & 1 \\
\hline 2005 & & & 2 & & 3 & 1 & & 1 & 3 & 10 \\
\hline 2006 & 1 & & & & & & 1 & 1 & 2 & 5 \\
\hline 2007 & 2 & & 3 & & & 2 & & 2 & 2 & 11 \\
\hline 2008 & 2 & & & & 2 & & 1 & & 3 & 8 \\
\hline 2009 & 4 & 2 & & 1 & & & & & 3 & 10 \\
\hline 2010 & 3 & 3 & 2 & & 1 & 2 & & & 15 & 26 \\
\hline 2011 & 1 & 1 & 1 & & 1 & & & 1 & 5 & 10 \\
\hline 2012 & 1 & 3 & & 2 & & & & & 4 & 10 \\
\hline 2013 & 2 & 1 & 2 & & & & 1 & 1 & 4 & 11 \\
\hline 2014 & 5 & & 2 & & & & & & 8 & 15 \\
\hline 2015 & 4 & 1 & & & & & 2 & 1 & 7 & 15 \\
\hline 2016 & 6 & 5 & & & & 1 & & & 7 & 19 \\
\hline 2017 & 2 & 3 & & 1 & & 1 & & & 1 & 8 \\
\hline 2018 & 5 & 4 & & 2 & & & 1 & & 1 & 13 \\
\hline 2019 & 6 & 7 & 1 & 5 & & 1 & & & 17 & 37 \\
\hline Toplam & 47 & 30 & 14 & 11 & 8 & 8 & 7 & 7 & 88 & 220 \\
\hline
\end{tabular}


Akreditasyon ile ilgili olarak yapılan tezlerin anabilim dallarına göre dağılımına ilişkin Tablo 6 hazırlanırken, 1994-2019 yılları arasında toplam tez sayısı 7 ve üzeri olan anabilim dalları tabloda kendi adıyla belirtilmiş, toplam tez sayısı 7'nin altında olan anabilim dalları ise diğer başlı̆̆ında birleştirilerek tabloya eklenmiştir. Tablo 6 incelendiğinde akreditasyon ile ilgili hazırlanan tezlerin en çok sırasıyla İşletme / İşletme Yönetimi (\%21.36) ve Sağlık Yönetimi / Sağlık Kurumları İşletmeciliği / Sağlıkta Kalite Geliştirme ve Akreditasyon (\%13.63) anabilim dallarında tamamlandığına ulaşılmıştır. Bunun yanında Elektrik Elektronik Mühendisliği / Bilgisayar Mühendisliği / Endüstri Mühendisliği / Biyomedikal Mühendislik / Gıda Mühendisliği, Eğitim Bilimleri, Eğitim Programları ve Öğretim, Hemşirelik / Hemşirelikte Yönetim, Mimarlık ve Eğitim Yönetimi anabilim dallarında da çok sayıda akreditasyonla ilişkili tez çalışmasının bulunduğu anlaşılmıştır. Diğer kategorisinde yer alanlar ise; Tarım Ekonomisi (4 tez), Toplam Kalite Yönetimi (3 tez), Fen Bilimleri (3 tez), Bilgisayar ve Öğretim Teknolojileri Eğitimi (2 tez) gibi çok sayıda anabilim dalından oluşmuştur. Diğer kategorisinde yer alan anabilim dallarından otuzu akreditasyon alanında yalnızca 1 tez yapmıştır. Diğer kategorisinde yer alan anabilim dallarından bazıları; bilişim, metalürji mühendisliği, maliye, eczacılık işletmeciliği ve mevzuatı, jeodezi, analitik kimya şeklindedir.

\section{Tezlerin Araştırma Yöntemlerine Göre Dağılımı}

Araştırmada yer alan tezlerin araştırma yöntemlerine göre dağılımı Tablo 7'de yer almaktadır.

Tablo 7. Araştırmada Yer Alan Tezlerin Araştırma Yöntemlerine Göre Dağılımı

\begin{tabular}{ccccc}
\hline \multirow{2}{*}{ Yil } & \multicolumn{3}{c}{ Araştırma Yöntemi } \\
\cline { 2 - 5 } & Nitel & Nicel & Karma & Toplam \\
\hline 1994 & 1 & & & 1 \\
1998 & 1 & & 1 \\
2000 & & 1 & 1 \\
2001 & 2 & 1 & 3 \\
2002 & & 1 & & 1 \\
2003 & 3 & 1 & & 4 \\
2004 & & 1 & & 1 \\
2005 & 5 & 4 & 1 & 10 \\
2006 & 1 & 4 & & 5 \\
2007 & 4 & 7 & & 11 \\
2008 & 3 & 5 & & 8 \\
\hline
\end{tabular}

\begin{tabular}{ccccc}
\hline \multirow{2}{*}{ Yil } & \multicolumn{4}{c}{ Araştırma Yöntemi } \\
\cline { 2 - 5 } & Nitel & Nicel & Karma & Toplam \\
\hline 2009 & 7 & 3 & & 10 \\
2010 & 13 & 13 & & 26 \\
2011 & 5 & 5 & & 10 \\
2012 & 4 & 5 & 1 & 10 \\
2013 & 5 & 6 & & 11 \\
2014 & 9 & 5 & 1 & 15 \\
2015 & 10 & 4 & 1 & 15 \\
2016 & 7 & 11 & 1 & 19 \\
2017 & 3 & 5 & & 8 \\
2018 & 7 & 5 & 1 & 13 \\
2019 & 17 & 19 & 1 & 37 \\
\hline Toplam & 107 & 106 & 7 & 220 \\
\hline
\end{tabular}

Tablo 7'de görüldüğü gibi, akreditasyon hakkında yapılan tezlerde en çok sırasıyla nitel (\%48.63) ve nicel araştırma yöntemleri (\%48.18) tercih edilmiştir. Tezlerde en az kullanılan araştırma yöntemi ise karma yöntem (\%3.18) olmuştur. Buna dayalı olarak akreditasyon konusunda yapılacak yeni tezlerde, nicel ve nitel yöntemlerin birlikte kullanımına ihtiyaç duyulduğu görülmüştür. Diğer taraftan, araştırma yöntemlerinin yıllara göre dağılımı incelendiğinde nicel ve nitel araştırma yöntemlerinin yıllara göre dağılımının dengeli olduğu, karma araştırma yönteminin ise son yıllarda kullanılmaya başlandığı görülmüştür. 


\section{Tezlerin Araştırma Modeline Göre Dağılımı}

Araştırmada yer alan tezlerin araştırma modeline göre dağılımı Tablo 8'de yer almaktadır.

Tablo 8. Araştırmada Yer Alan Tezlerin Araştırma Modeline Göre Dağılımı

\begin{tabular}{|c|c|c|c|c|c|c|c|c|c|}
\hline \multirow[b]{2}{*}{ Yal } & \multicolumn{9}{|c|}{ Araştırma Modeli / Deseni } \\
\hline & Tarama & $\begin{array}{c}\text { Durum } \\
\text { Çal. }\end{array}$ & Betimsel & Deneysel & $\begin{array}{l}\text { Olgu } \\
\text { bilim }\end{array}$ & $\begin{array}{c}\text { Eş } \\
\text { Zamanlı } \\
\text { Karma } \\
\end{array}$ & $\begin{array}{l}\text { Yakinsayan } \\
\text { Karma }\end{array}$ & $\begin{array}{c}\text { Çok } \\
\text { Aşamalı } \\
\text { Karma } \\
\end{array}$ & Top. \\
\hline 1994 & 1 & & & & & & & & 1 \\
\hline 1998 & 1 & & & & & & & & 1 \\
\hline 2000 & 1 & & & & & & & & 1 \\
\hline 2001 & 3 & & & & & & & & 3 \\
\hline 2002 & & & & 1 & & & & & 1 \\
\hline 2003 & 2 & 2 & & & & & & & 4 \\
\hline 2004 & & 1 & & & & & & & 1 \\
\hline 2005 & 6 & 3 & & & & 1 & & & 10 \\
\hline 2006 & 3 & & 2 & & & & & & 5 \\
\hline 2007 & 7 & 2 & 2 & & & & & & 11 \\
\hline 2008 & 6 & 2 & & & & & & & 8 \\
\hline 2009 & 8 & & 2 & & & & & & 10 \\
\hline 2010 & 16 & 3 & 2 & 5 & & & & & 26 \\
\hline 2011 & 7 & & 2 & 1 & & & & & 10 \\
\hline 2012 & 5 & & 2 & 1 & 1 & 1 & & & 10 \\
\hline 2013 & 4 & 2 & 2 & 3 & & & & & 11 \\
\hline 2014 & 9 & & 3 & 2 & & 1 & & & 15 \\
\hline 2015 & 8 & 4 & 1 & 1 & & & 1 & & 15 \\
\hline 2016 & 10 & 7 & & 1 & & 1 & & & 19 \\
\hline 2017 & 8 & & & & & & & & 8 \\
\hline 2018 & 8 & & 3 & & 1 & 1 & & & 13 \\
\hline 2019 & 15 & 5 & 8 & 6 & 2 & & & 1 & 37 \\
\hline Top. & 128 & 31 & 29 & 21 & 4 & 5 & 1 & 1 & 220 \\
\hline
\end{tabular}

Tablo 8 incelendiğinde, tezlerde sıklıkla kullanılan araştırma modelinin tarama (\%58.18) olduğuna ulaşılmıştır. Akreditasyon konusunda yapılan tezlerde nitel ve nicel araştırma yöntemlerinin kullanımına paralel olarak çoğunlukla tarama modelinin tercih edildiği belirlenmiştir. Araştırma kapsamında en çok tercih edilen diğer araştırma modelleri ise sırasıyla ise durum çalışması, betimsel, deneysel, olgubilim, eş zamanlı karma, yakınsayan karma ve çok aşamalı karma şeklinde ortaya çıkmıştır. Akreditasyon ile ilgili yapılan tezlerde karma yönteminin kullanımının az olmasına bağlı olarak, karma araştırma modellerinin de en az tercih edilen araştırma modelleri olduğuna ulaşılmıştır.

\section{Tezlerin Veri Toplama Araçlarına Göre Dağılımı}

Araştırmada yer alan tezlerin veri toplama araçlarına göre dağılımı Tablo 9'da yer almaktadır. 
Tablo 9. Araştırmada Yer Alan Tezlerin Veri Toplama Araçlarına Göre Dağılımı

\begin{tabular}{|c|c|c|c|c|c|c|}
\hline \multirow[b]{2}{*}{ Yil } & \multicolumn{6}{|c|}{ Veri Toplama Araçları } \\
\hline & Anket & $\begin{array}{c}\text { Doküman İnceleme } \\
\text { Formu }\end{array}$ & $\begin{array}{c}\text { Görüşme } \\
\text { Formu }\end{array}$ & $\begin{array}{c}\text { Ölçek/Ölçüm } \\
\text { Formu }\end{array}$ & $\begin{array}{l}\text { Gözlem } \\
\text { Formu }\end{array}$ & Toplam \\
\hline 1994 & & 1 & & & & 1 \\
\hline 1998 & & 1 & & & & 1 \\
\hline 2000 & 1 & & & & & 1 \\
\hline 2001 & 1 & 2 & & & & 3 \\
\hline 2002 & 1 & & & & & 1 \\
\hline 2003 & 1 & 2 & 1 & & & 4 \\
\hline 2004 & 1 & & & & & 1 \\
\hline 2005 & 3 & 3 & 2 & 2 & 1 & 11 \\
\hline 2006 & 4 & 1 & & & & 5 \\
\hline 2007 & 5 & 4 & & 2 & & 11 \\
\hline 2008 & 5 & 3 & & & & 8 \\
\hline 2009 & 2 & 6 & 1 & 1 & & 10 \\
\hline 2010 & 8 & 9 & 3 & 5 & 1 & 26 \\
\hline 2011 & 4 & 4 & 1 & 1 & & 10 \\
\hline 2012 & 4 & 3 & 2 & 2 & & 11 \\
\hline 2013 & 3 & 4 & 1 & 3 & & 11 \\
\hline 2014 & 4 & 8 & 2 & 2 & & 16 \\
\hline 2015 & 4 & 9 & 2 & 1 & & 16 \\
\hline 2016 & 11 & 5 & 3 & 1 & & 20 \\
\hline 2017 & 4 & 2 & 1 & 1 & & 8 \\
\hline 2018 & 6 & 3 & 5 & & & 14 \\
\hline 2019 & 14 & 8 & 10 & 6 & & 38 \\
\hline Toplam & 86 & 78 & 34 & 27 & 2 & 227 \\
\hline
\end{tabular}

Tablo 9'a göre tezlerde sıklıkla kullanılan veri toplama araçlarının anket (\%37.88) ve doküman inceleme formu (\%34.36) olduğuna ulaşılmıştır. Bu durum, tezlerde kullanılan araştırma yöntemlerine ilişkin elde edilen bulgularla da paralellik göstermektedir. Tezlerde en az kullanılan veri toplama araçları ise gözlem formu ve ölçek/ölçüm formu olmuştur. Diğer taraftan, Tablo 9'da yer alan toplam veri toplama aracı sayısının, araştırmada yer alan toplam tez sayısından fazla olduğuna ulaşılmıştır. $\mathrm{Bu}$ durum karma araştırma yöntemiyle yapılan tezlerin bulunduğu yıllarda veri toplama aracı sayısının artmasıyla ilgilidir. Karma yöntem araştırmaları nitel ve nicel araştırmaları birlikte kullanmayı, dolayısıyla nitel ve nicel veri toplama araçlarını da birlikte kullanmayı gerektirmektedir. 2005, 2012, 2014, 2015, 2016, 2018 ve 2019 yıllarında karma araştırma yöntemleri ile gerçekleştirilen tezlerde hem nicel hem nitel veri toplama araçlarının kullanılmasına bağlı olarak toplam veri toplama aracı sayısı toplam tez sayısından fazla bulunmuştur.

\section{Tezlerin Örneklemlerine Göre Dağılımı}

Araştırmada yer alan tezlerin örneklemlerine göre dağılımı Tablo 10' da yer almaktadır. 
Tablo 10. Araştırmada Yer Alan Tezlerin Örneklemlerine Göre Dağılımı

\begin{tabular}{|c|c|c|c|c|c|c|c|c|c|c|c|c|}
\hline \multirow[b]{2}{*}{ Yil } & \multicolumn{12}{|c|}{ Örneklem } \\
\hline & $\frac{a}{0}$ & 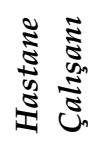 & 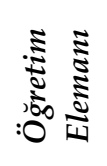 & 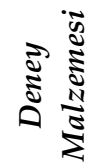 & 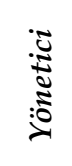 & 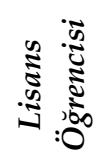 & $\frac{\mathbb{s}}{\frac{D}{d}}$ & 包 & $\frac{\sqrt{N}}{\sqrt{5}}$ & 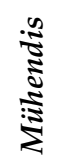 & $\stackrel{\pi}{2}$ & $\frac{5}{\frac{5}{5}}$ \\
\hline 1994 & 1 & & & & & & & & & & & 1 \\
\hline 1998 & 1 & & & & & & & & & & & 1 \\
\hline 2000 & & & 1 & & & 1 & & & & & & 2 \\
\hline 2001 & 2 & 1 & & & & & & & & & & 3 \\
\hline 2002 & & & 1 & & & & & & & & & 1 \\
\hline 2003 & 2 & 1 & & & & 1 & & & & & & 4 \\
\hline 2004 & & & & & & & 1 & & & & & 1 \\
\hline 2005 & 2 & 1 & 2 & 2 & 2 & 2 & & 2 & & & & 13 \\
\hline 2006 & 1 & 1 & & & 1 & 1 & & & & 1 & & 5 \\
\hline 2007 & 5 & 3 & 1 & 2 & 2 & & & 1 & 1 & & & 15 \\
\hline 2008 & 5 & 2 & 3 & & & 1 & & & & & & 11 \\
\hline 2009 & 7 & 3 & 1 & 1 & & & & & & & & 12 \\
\hline 2010 & 11 & 6 & 1 & 5 & 2 & 2 & & 2 & & & & 29 \\
\hline 2011 & 4 & 2 & 2 & 1 & & & 1 & & & & & 10 \\
\hline 2012 & 2 & 2 & 2 & 1 & & 2 & 1 & & 1 & & & 11 \\
\hline 2013 & 3 & 2 & 1 & 3 & 1 & 2 & & 1 & & & & 13 \\
\hline 2014 & 8 & 3 & & 3 & & & 1 & & 1 & & & 16 \\
\hline 2015 & 9 & 1 & 1 & 1 & 1 & 3 & & 1 & & & & 17 \\
\hline 2016 & 5 & 10 & 1 & 1 & 3 & 1 & & & & & & 21 \\
\hline 2017 & 2 & 5 & 1 & & & 1 & & & & & & 9 \\
\hline 2018 & 4 & 5 & 4 & & 1 & 2 & & & & & & 16 \\
\hline 2019 & 9 & & 7 & 7 & 10 & 1 & 4 & 1 & & 1 & 1 & 41 \\
\hline Toplam & 83 & 48 & 29 & 27 & 23 & 20 & 8 & 8 & 3 & 2 & 1 & 252 \\
\hline
\end{tabular}

Tablo 10 incelendiğinde akreditasyon hakkında yapılan tezlerin örneklemlerini en çok dokümanların (\%32.93) oluşturduğuna ulaşılmıştır. Doküman olarak ulusal ve uluslararası akreditasyon kuruluşlarının belgeleri, akreditasyon sürecine yönelik devlet politikaları, akreditasyon sürecine ilişkin rapor ve araştırmalar gibi belgelerin yer aldığı görülmüştür. Bunun yanında en çok tercih edilen örneklemler sırasıyla hastane çalışanı, öğretim elemanı, deney malzemesi, yönetici, lisans öğrencisi, hasta ve öğretmen şeklinde ortaya çıkmıştır. Örneklem grubunun dağılımı incelendiğinde, akreditasyon ile ilgili yapılan tezlerin araştırma yöntemleri ve veri toplama araçlarıyla ilgili elde edilen bulgularla paralellik gösterdiği anlaşılmaktadır. Örneklem grupları içerisinde en az tercih edilenler ise uzman, mühendis ve veli olmuştur. Bu örneklem çeşitlerinin akreditasyon konusunda diğer örneklem gruplarına göre veri kaynağı olarak görülmediği söylenebilir. Diğer taraftan, toplam örneklem sayısının araştırmada yer alan toplam tez sayısından fazla olduğuna ulaşılmıştır. Bu durum, bir tezde farklı örneklem gruplarından aynı anda yararlanıldığını göstermektedir. Tezlerde örneklem grubunda çeşitlilik sağlanmasının, araştırmaların geçerliğini desteklediği düşünülmektedir.

\section{Tezlerin Konulara Göre Dağılımı}

Araştırmada yer alan tezlerin konulara göre dağılımı Tablo 11'de yer almaktadır. 
Tablo 11. Araştırmada Yer Alan Tezlerin Araştırma Konularına Göre Dağılımı

\begin{tabular}{|c|c|c|c|c|c|c|c|}
\hline \multirow[b]{2}{*}{ Yillar } & \multicolumn{7}{|c|}{ Konular } \\
\hline & Să̆lık & Ĕgitim & Mühendislik & $\begin{array}{c}\text { Akreditasyon } \\
\text { Uygulamalarının } \\
\text { Değerlendirilmesi }\end{array}$ & Issletme & $\begin{array}{c}\text { Akreditasyon } \\
\text { Kuruluşlarının } \\
\text { İşleyişi } \\
\end{array}$ & Toplam \\
\hline 1994 & & & & & & 1 & 1 \\
\hline 1998 & & & & & & 1 & 1 \\
\hline 2000 & & 1 & & & & & 1 \\
\hline 2001 & & 2 & & 1 & & & 3 \\
\hline 2002 & & 1 & & & & & 1 \\
\hline 2003 & 1 & 3 & & & & & 4 \\
\hline 2004 & 1 & & & & & & 1 \\
\hline 2005 & 1 & 4 & 2 & 1 & 2 & & 10 \\
\hline 2006 & 1 & 3 & & & 1 & & 5 \\
\hline 2007 & 3 & 3 & 3 & & 1 & 1 & 11 \\
\hline 2008 & 4 & 3 & 1 & & & & 8 \\
\hline 2009 & 6 & 2 & & & 1 & 1 & 10 \\
\hline 2010 & 8 & 5 & 7 & 3 & 1 & 2 & 26 \\
\hline 2011 & 3 & 4 & 2 & 1 & & & 10 \\
\hline 2012 & 4 & 4 & & 2 & & & 10 \\
\hline 2013 & 3 & 3 & 5 & & & & 11 \\
\hline 2014 & 6 & 2 & 6 & & 1 & & 15 \\
\hline 2015 & 3 & 5 & 1 & 2 & 3 & 1 & 15 \\
\hline 2016 & 10 & 2 & 1 & 2 & 4 & & 19 \\
\hline 2017 & 7 & 1 & & & & & 8 \\
\hline 2018 & 6 & 5 & & 2 & & & 13 \\
\hline 2019 & 14 & 8 & 9 & 3 & 2 & 1 & 37 \\
\hline Toplam & 81 & 61 & 37 & 17 & 16 & 8 & 220 \\
\hline
\end{tabular}

Tablo 11 incelendiğinde, akreditasyon ile ilgili yapılan tez çalışmalarının en çok sırasıyla sağlık (\%36.81) ve eğitim (\%27.72) alanlarında yapıldı̆̆ına ulaşılmıştır. Buna dayalı olarak sağlık alanında, hastanelerin ve sağlık kuruluşlarının akreditasyon sürecini tamamlamaya yönelik tezlerin sıklıkla yapıldığı anlaşılmıştır. Aynı zamanda incelenen tezlerin örneklem grubu ve tez konuları hakkında elde edilen bulguların birbirini desteklediği anlaşılmaktadır. Hastane çalışanları ve hastalardan oluşan örneklem grubunun, sağlık alanında yapılan tezlerin örneklem grubunu çoğunlukla oluşturduğu belirlenmiştir. Bunun yanında eğitim alanında akreditasyona yönelik yapılan tezler ile özellikle yükseköğretim ve öğretmen yetiştirme konularının çalışıldığı belirlenmiştir. Bu durum, örneklem grubunda öne çıkan öğretim elemanı, lisans öğrencisi, öğretmen gibi katılımcıların genellikle eğitime yönelik akreditasyon çalışmalarında yer aldığını göstermektedir. Akreditasyon ile ilgili yapılan tezlerin konulara göre dağılımı incelendiğinde mühendislik, akreditasyon uygulamalarının değerlendirilmesi, işletme, akreditasyon kuruluşlarının işleyişi gibi farklı çalışma alanlarında da akreditasyona ilişkin araştırmaların yapıldı̆̆ı belirlenmiştir. Özellikle mühendislik alanındaki tezlerde laboratuvarların akreditasyonu, akredite olan ve olmayan laboratuvarlarda yapılan analizler konuları ön plana çıkmıştır. Bunun yanında ülkemizde yapılan akreditasyon 
uygulamaların değerlendirilmesi, uluslararası akreditasyon süreçleri ile karşılaştırılması, işletmelerin akreditasyon sürecindeki uygulamalarının incelenmesi, ulusal ve uluslararası akreditasyon kuruluşlarının yapı ve işleyişine ilişkin dokümanların analizi konuları tezlerin diğer araştırma konularını oluşturmuştur. Bu araştırmalar sosyal bilimler, fen bilimleri, sağlık bilimleri gibi her alanda kurumlara ve işletmelere yönelik akreditasyon değerlendirmeleri yaptığı için ayrı başlıklarda ele alınmıştır. Bu çalışmalar akreditasyon kuruluşlarının yapı ve işleyişi hakkında incelemelerden de oluştuğu için sağlık, eğitim, mühendislik gibi bir sektör altında değerlendirilememiştir.

\section{Sonuç ve Tartışma}

Akreditasyon ile ilgili yapılan lisansüstü tezlerin incelendiği bu araştırmada elde edilen bulgulara dayalı olarak akreditasyon konusunda yapılan ilk lisansüstü tez çalışmasının 1994 yılında tamamlandığına ulaşılmıştır. Bu nedenle araştırma kapsamına 1994-2019 yılları arasında tamamlanan ve erişime açık lisansüstü tezler dahil edilmiştir. Tezlerin yıllara göre dağılımı incelendiğinde; özellikle 2005 yılı ve sonrasında yapılan tezlerin, önceki yıllara göre artış gösterdiğine ulaşılmıştır. 2005 yılında akreditasyon hakkında tezlerin artış göstermesi, Yükseköğretim Kurulunun çalışmalarıyla ilişkili bulunmuştur. 2005 yılında yükseköğretimde eğitim, öğretim ve araştırma faaliyetlerinin kalitesinin geliştirilmesi amacıyla Yükseköğretim Kurumlarında Akademik Değerlendirme ve Kalite Geliştirme Yönetmeliği yayınlanmış ve kalite geliştirme çalışmalarının düzenlenmesinden sorumlu olan Yükseköğretim Kurumları Akademik Değerlendirme ve Kalite Geliştirme Komisyonu kurulmuştur (YÖK, 2020b). Akreditasyon sürecine yönelik atılan bu önemli adımlar, yükseköğretimde akreditasyon çalışmalarının daha sistemli ve düzenli yapılmasına katkıda bulunmuştur. Bu nedenle 2005 yılı ve sonrasında akreditasyon konusundaki tezlerin artış gösterdiği görülmüştür. Akreditasyon hakkında yapılan bu tezlerin genellikle yüksek lisans düzeyinde (\%75.90) yapıldığı belirlenmiştir. Araştırmada yer alan kadın (\%50.45) ve erkek (\%49.54) tez yazarlarının birbirine paralel olduğu görülmüştür. Bu durum, akreditasyon konusunda cinsiyete yönelik herhangi bir farklılık yaratmayan ortak bir çalışma alanı olduğunu göstermektedir.

Akreditasyon hakkında yapılan tezlerin üniversitelere ve enstitülere göre dağılımında elde edilen bulgular değerlendirildiğinde; tezlerin en çok Gazi Üniversitesi'nde (\%8.63), Dokuz Eylül Üniversitesi'nde (\%8.18) ve Marmara Üniversitesi'nde (\%7.72) yapıldığı anlaşılmaktadır. Aynı zamanda tezlerin en çok sosyal bilimler enstitüsünde (\%42.72) tamamlandığı belirlenmiştir. Bu bulgulara dayalı olarak, akreditasyon ile ilgili yapılan tezlerin Türkiye'nin en eski ve köklü üniversitelerinde daha yaygın çalışıldığı söylenebilir. Aynı zamanda üç üniversitede de sosyal bilimler enstitülerinin 1982 yılında kurulduğu belirlenmiştir (Marmara Üniversitesi 2020; Wikipedia, 2020a, 2020b). Üç üniversitenin de Türkiye'nin en eski sosyal bilimler enstitülerine ev sahipliği 
yapıyor olması nedeniyle, yapılan tez çalışmalarının çoğunluğunun bu üniversitelerde tamamlandığı anlaşılmıştır.

Akreditasyon konusunda yapılan tezlerin genellikle sosyal bilimler enstitülerinde tamamlanmasıyla ilişkili olarak, tezlerin genellikle İşletme / İşletme Yönetimi (\%21.36) anabilim dallarında tamamlandığı belirlenmiştir. Akreditasyon sürecinden sorumlu kurum ve kuruluşların yapısı, işleyişi ve akreditasyon sürecinde gerçekleştirilen uygulamaların işletme anabilim dalının temel çalışma konularından biri olması nedeniyle tezlerin çoğunlukla bu anabilim dalında tamamlandığ1 görülmüştür. Bunun yanında işletmelerin rekabet ortamında müşterilerini memnun etmek için ürettikleri mal ve hizmetlerde kalite standartlarını sürekli geliştirmeleri gerekmektedir. Aynı zamanda iş gücü piyasasındaki her işletmenin akreditasyon sürecine katılması, ulusal ve uluslararası düzeyde kalite standartlarını geliştirmesi beklenmektedir. Bu nedenle işletme ve işletme yönetimi alanlarında akreditasyon çalışmalarının önemi büyüktür (Gencel, 2001; Harman, 2018).

1994-2019 yılları arasında akreditasyon konusunda tamamlanan tezlerin yöntemleri incelendiğinde ise, nitel (\%48.63) ve nicel (\%48.18) araştırma yöntemlerinin eşit oranda kullanıldığ1 anlaşılmıştır. Buna dayalı olarak tezlerde sıklıkla tarama araştırma modelinin (\%58.18) tercih edildiği belirlenmiştir. Özellikle akreditasyon ile ilgili yapılan ulusal ve uluslararası çalışmaların incelendiği ve karşılaştırıldığı tezlerin çoğunlukta olması nedeniyle, tarama modelinin yaygın kullanıldığı görülmüştür. Aynı zamanda tarama araştırmalarının hem nitel hem nicel yöntemlere uygun olması tercih edilme nedenlerinden bir diğeridir. Diğer taraftan tarama araştırmalarının felsefesine uygun olarak akreditasyon ile ilgili yapılan tezlerde en sık kullanılan veri toplama araçları anket (\%37.88) ve doküman inceleme formu (\%34.36) olmuştur. Buna dayalı olarak nitel yöntemlerin kullanıldığı tezlerde genellikle doküman inceleme formunun, nicel yöntemlerin kullanıldığı tezlerde ise genellikle anketten yararlanıldığına ulaşılmıştır. Bunun yanında elde edilen bulgulara dayalı olarak, akreditasyon konusunun hem nitel hem nicel veri toplama araçlarına elverişli olması nedeniyle, yapılacak yeni araştırmalarda karma araştırma yöntemlerinin daha çok kullanılmasına ihtiyaç bulunduğu anlaşılmıştır. Akreditasyon hakkında tamamlanan tezlerin örneklemleri incelendiğinde, genellikle dokümanlardan yararlanıldığı görülmüştür. Akreditasyon konusunda tezlerin son yıllarda artış göstermesine paralel olarak yapılan tez çalışmalarında öncelikle akreditasyonla ilişkili var olan çalışmaların, belgelerin, araştırma sonuçlarının, raporların incelendiği belirlenmiştir. Bu nedenle dokümanlar, örneklemler içinde en çok yararlanılan grup olarak öne çıkmıştır. Ancak son 2016 yılından itibaren örneklem dağılımları incelendiğinde, dokümanların diğer örneklemlere göre kullanımının azaldığı görülmüştür. Bu durum, akreditasyon ile ilgili yapılan son tez çalışmalarında doküman yerine kişi ve kurumlardan yararlanıldığını göstermektedir. Yapılacak yeni araştırmalarda 
da farklı örneklem gruplarından yararlanılarak akreditasyon konusunda farklı bilgi ve deneyimlere dayalı bulguların sunulması önerilmektedir.

Son olarak incelenen lisansüstü tezlerde genellikle sağlık (\%36.81) ve eğitim (\%27.72) akreditasyonu hakkında araştırmaların yapıldığına ulaşılmıştır. Akreditasyon hakkında yapılan tezlerin genellikle işletme anabilim dalında gerçekleşmesiyle ilişkili olarak sağlık ve eğitim sektörlerinin işletme alanında sıklıkla çalışılan konular olduğu görülmüştür. Türkiye'de sağlık alanında akreditasyon standartlarının 2012 yılında resmi olarak başladığını belirten Gökmen-Kavak (2018), TÜSKA'nın (Türkiye Sağlık Hizmetleri Kalite ve Akreditasyon Enstitüsü) kurulması ile akreditasyon çalışmalarının arttığını belirtmiştir. Hoş (2016) ise sağlıkta akreditasyon en fazla hastanelerde uygulandığını vurgulamaktadır. Eğitim alanında yapılan tezlerde ise, genellikle üniversitelerde akreditasyon çalışmalarının etkisi, akreditasyona yönelik uygulamaların değerlendirilmesi, akreditasyon konusunda yapılan çalışmaların karşılaştııılması şeklinde konuların ele alındığı görülmüştür. Öğretmen eğitiminde standartlar ve akreditasyon hakkında yapılan çalışmaların, öğretmen yetiştirme sürecinde niteliği artıracağını belirten Kavak (1999), aynı zamanda yükseköğretimde öğretmen yetiştiren kurumların birbiriyle rekabet edebilmesi için kalite standartlarını korumaları gerektiğini belirtmektedir. Bu yönüyle eğitim konusunda yapılan akreditasyon çalışmalarında öğretmen eğitimi ve öğretmen eğitimi programlarının daha çok yer verilmesi önerilebilir. Diğer taraftan öğretmen yetiştiren kurumların ürün ya da hizmet yönünden yeterli düzeye getirilmesinde akreditasyonun gerekliliği vurgulanmaktadır (Adıgüzel ve Sağlam, 2009). Bu yönüyle eğitimde akreditasyon çalışmalarını yaygınlaştırırken öğretmen yetiştiren kurumlarda ve öğretmen eğitimi programlarında akreditasyon çalışmalarına öncelik verilmesi önerilmektedir.

\section{Kaynaklar}

Adıgüzel, A., \& Sağlam, M. (2009). Program standards and accreditation in the teacher education. Inonu University Journal of the Faculty of Education, 10(3), 83-103.

Aktan, C. C., \& Gencel, U. (2010). Yüksek öğretimde akreditasyon. Organizasyon ve Yönetim Bilimleri Dergisi, 2(2), 137-146.

Cengiz, C. (2018). Sağlık hizmetlerinde akreditasyon programları ve Tüska. Sağllkta Kalite ve Akreditasyon Dergisi, 1(1), 21-26.

Creswell, J. W. (2017). Eğitim araştırmalar nicel ve nitel araştırmanın planlanması, yürütülmesi ve değerlendirilmesi (H. Ekşi, Çev. Ed.). İstanbul: EDAM.

Doğan, İ. (1999). Eğitimde kalite ve akreditasyon sorunu: Eğitim fakülteleri üzerine bir deneme. Kuram ve Uygulamada Ĕ̆itim Yönetimi, 20(20), 503-519. 
Gencel, U. (2001). Yükseköğretim hizmetlerinde toplam kalite yönetimi ve akreditasyon. Dokuz Eylül Üniversitesi Sosyal Bilimler Enstitüsü Dergisi, 3(3), 164-218.

Gökmen-Kavak, D. (2018). Türkiye Sağlık Hizmetleri Kalite ve Akreditasyon Enstitüsü sağlıkta akreditasyon standartları. Sağlıkta Kalite ve Akreditasyon Dergisi, 14-20.

Günay, D. (2003). Akreditasyonun neliği ve mühendislik eğitimi üzerindeki etkisi. https://www.researchgate.net/profile/DurmusGunay/publication/317662165 Akreditasyonun Neligi ve Muhendislik Egitimi Uzerindeki Etkisi/links/5947bcefa6fdccfa594deb84/Akreditas yonun-Neligi-ve-Muehendislik-Egitimi-Uezerindeki-Etkisi.pdf sayfasından erişilmiştir.

Harman, A. (2018). Müşteri ilişkileri yönetimi açısından akreditasyon ve kalite yönetim sisteminin Kırıkkale Üniversitesi'nde çalışan iç müşteriler tarafından algılanmasına yönelik karşılaştırmalı bir araştırma. (Yüksek lisans tezi). https://tez.yok.gov.tr sayfasından erişilmiştir.

Hoş, C. (2016). Sağlıkta zoru başarmak: Sağl1k sektöründe akreditasyon. Süleyman Demirel Üniversitesi Sosyal Bilimler Enstitüsü Dergisi, CIEP Özel Sayısı, 498-533.

Işık, S., \& Beykoz, S. Y. (2018). Türk yükseköğretiminde yeni bir arayış: kalite güvence sistemi. Kastamonu University Journal of Faculty of Economics and Administratives Sciences, 20(3), 7-22.

Kavak, Y. (1999). Öğretmen eğitiminde yeni bir yaklaşıma doğru: standartlar ve akreditasyon. Kuram ve Uygulamada Ĕ̆itim Yönetimi, 19(19), 313-324.

Marmara Üniversitesi (2020, January 1). Institute of Social Sciences. https://sbe.marmara.edu.tr/7 sayfasından erişilmiştir.

Özçiçek, Y., \& Karaca, A. (2019). Yükseköğretim kurumlarında kalite ve akreditasyon: Mühendislik eğitim programlarının değerlendirilmesi. Fırat Üniversitesi Uluslararası İktisadi ve İdari Bilimler Dergisi, 3(1), 114-149.

Sönmez, V., \& Alacapınar, F. G. (2013). Örneklendirilmiş bilimsel araştırma yöntemleri. (2. Baskı). Ankara: An1.

Uçar, E. M., \& Levent, F. (2017). Yükseköğretimde uluslararası akreditasyon deneyimi: bir vakıf üniversitesi yabancı diller hazırlık okulu örneği. The Journal of International Social Research, 10(52), 846-857.

Wikipedia (2020a, January 4). Gazi University Institute of Social Sciences. https://tr.wikipedia.org/wiki/Gazi \%C3\%9Cniversitesi Sosyal Bilimler Enstit\%C3\%BCs\%C3 \%BC sayfasından erişilmiştir.

Wikipedia (2020b, February 7). Dokuz Eylül University Institute of Social Sciences. https://tr.wikipedia.org/wiki/Dokuz Eyl\%C3\%BCl \%C3\%9Cniversitesi sayfasından erişilmiştir.

Yıldırım, A., \& Şimşek, H. (2013). Sosyal bilimlerde nitel araştırma yöntemleri (9. Baskı). Ankara: Seçkin. 
YÖK (2020a, Şubat 10). European Association for Quality Assurance in Higher Education (ENQA). https://yokak.gov.tr/Uluslararasilasma/Uyelikler sayfasından erişilmiştir.

YÖK (2020b, Ocak 20). Quality Assurance.

https://uluslararasi.yok.gov.tr/uluslararasilasma/bologna/bologna-s\%C3\%BCreci-ana-faaliyetalanlar\%C4\%B1/kalite-guvencesi sayfasından erişilmiştir.

\section{Extended Summary}

One of the prominent research areas in our higher education system in recent years is accreditation. With accreditation studies and practices, it is aimed to increase the quality in education, to spread transparency and to make educational institutions competitive with each other. In this respect, it is seen that accreditation studies in different disciplines in all areas of higher education are increasing. Theses related to accreditation are common, especially at the graduate level. Continuing accreditation studies in different research and application areas in the fields of education, engineering, business and health contributes to the widespread and development of accreditation. It is especially important to include accreditation in graduate thesis studies where comprehensive and in-depth research is conducted. At the same time, the need to examine, evaluate and compare thesis studies together arises. In this way, it will be easier to guide and direct new research based on the studies. On the other hand, new studies that complement and advance each other instead of repetitive studies will be paved. With this research based on all these reasons, it is aimed to evaluate the graduate theses in the field of accreditation and to examine these theses together in a general framework based on the year they are completed, the methodology they used, the basic topics they dealt with. Especially the absence of such a comprehensive study in the literature reveals the importance and necessity of this study. The field of accreditation is one of the current research areas that are and will continue to be studied in postgraduate theses. In this respect, this research was designed according to a descriptive research model in which a living phenomenon is dealt with. At the same time, the research shows qualitative research characteristics.

The working group of the research consists of 220 master's and doctoral theses, which were held between 1994 and 2019 and are open to access at the National Thesis Center. For this reason, sampling was not used in the study, and the entire universe was included in the study. In the collection of the theses that constitute the sample of the research, the determination table was used as the data collection tool. Theses were classified in two dimensions, namely the keyword and the years when the thesis was completed, through the table of indicators prepared by the researcher. The key word used in the selection of theses in the statement table is "accreditation". Document analysis was used while analyzing the data in the study. 
The findings obtained as a result of the document analysis are presented in tables under the heading of findings. It was determined that the postgraduate theses discussed in the research mostly belong to 2005 and later. This situation has been found to be related to the studies of the Higher Education Council regarding the accreditation studies in higher education in our country. Especially after 2005, it can be said that the legal regulations regarding accreditation paved the way for the studies carried out in this field. In addition, it is understood that the theses are generally completed at the master's level $(75.90 \%)$. As one of the new research areas, it is thought that accreditation is generally studied at the master's level, but doctoral dissertations will be more in the future. Especially the findings and results obtained from the studies conducted at the master's level will be the source of new doctoral thesis researches. In addition, the number of female and male researchers who completed the theses is close to each other. The existence of accreditation researches and practices in different sectors and disciplines explains the close ratio of female and male researchers in the field of accreditation. Another finding obtained in the research is related to the institutions where the theses were completed. Theses made were mostly completed in social sciences institutes. It is recommended that other institutes in higher education such as science institutes and health sciences include thesis studies in the field of accreditation. When the methods used in the theses were examined, it was seen that qualitative $(48.63 \%)$ and quantitative $(48.18 \%)$ methods were preferred at a similar rate to each other. At the same time, documents were generally used in postgraduate theses. recognition of accreditation in Turkey and the world, understanding and analysis of existing research said that in the process of so-called because documents often preferred. In the last theses, it was found that researches were generally carried out in the field of health $(36.81 \%)$ and education $(27.72 \%)$ accreditation. Based on this, it can be said that the main subjects for accreditation in graduate theses should be more diversified. Maintaining thesis studies on accreditation especially in different subjects and titles other than health and education may contribute to the spread of accreditation practices in these fields. Based on all these, it is believed that the findings obtained in the research will guide researchers who want to study accreditation, especially in graduate theses, and will be useful in spreading accreditation research in higher education. 
Ek 1. Belirtke Tablosu

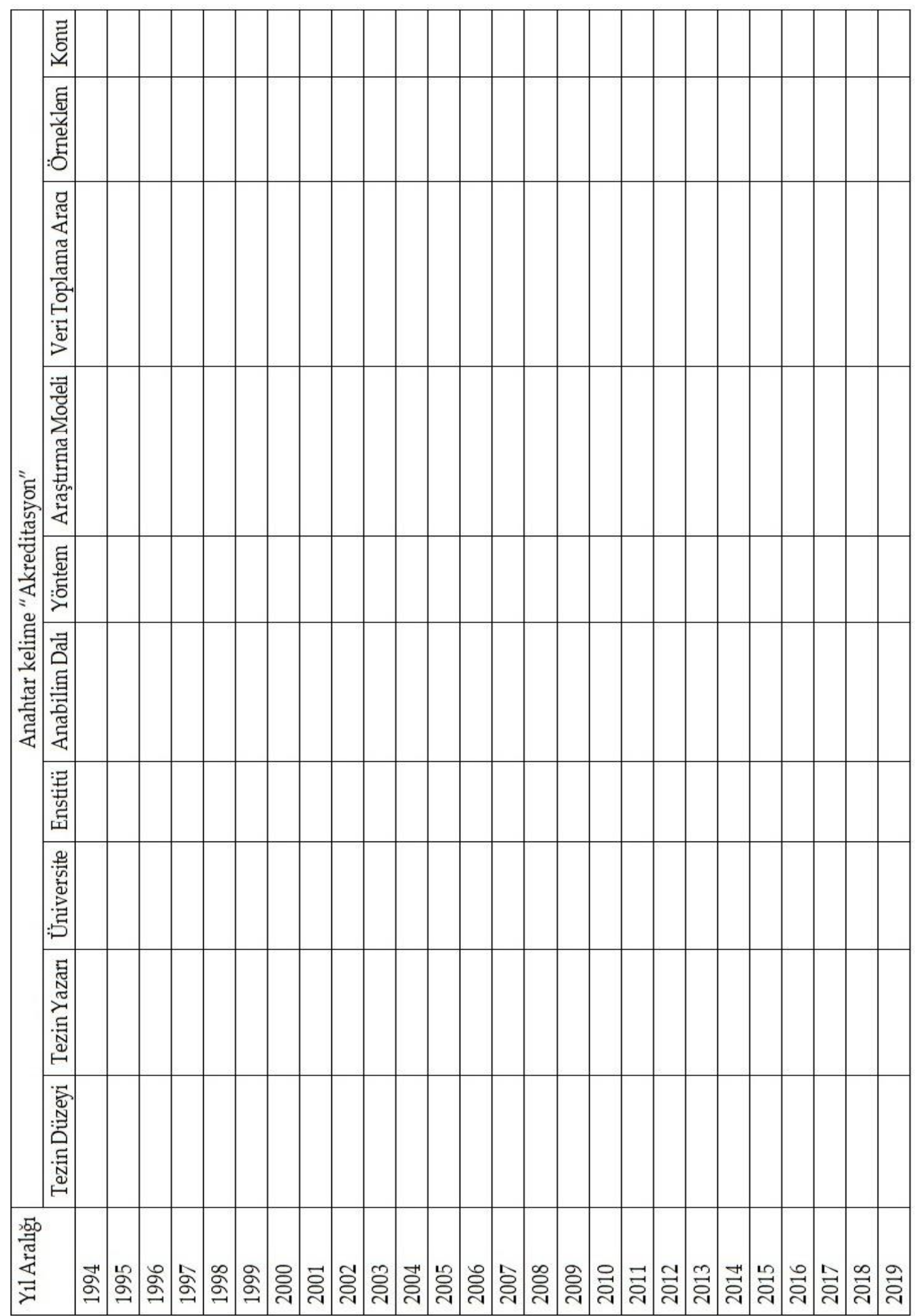




\section{Araştırmacıların Katkı Oranı Beyanı}

$\mathrm{Bu}$ araştırmanın planlanması, yürütülmesi ve yazılı hale getirilmesinde sadece tek bir araştırmacı yer almıştır.

\section{Destek ve Teşekkür Beyanı}

$\mathrm{Bu}$ araştırmada herhangi bir kurum, kuruluş ya da kişiden destek alınmamıştır.

\section{Çatışma Beyanı}

Araştırmacının araştırma ile ilgili diğer kişi ve kurumlarla herhangi bir kişisel ve finansal çıkar çatışması yoktur.

\section{Etik Kurul Beyanı}

$\mathrm{Bu}$ araştırma, Kırıkkale Üniversitesi Sosyal ve Beşeri Bilimler Araştırmaları Etik Kurulunun 18.12.2020 tarihli 06 oturum numaralı toplantısında alınan onay ile yürütülmüştür.

\section{Araştırmacinın Notu}

Bu çalışmada incelemeye alınan tezlere ilişkin ayrıntılı bilgiye ulaşmak isteyen okuyucular yazarla iletişime geçebilir. 